\title{
Association Between the Neurogenic Bladder Symptom Score and Urodynamic Examination in Multiple Sclerosis Patients With Lower Urinary Tract Dysfunction
}

\author{
Eugenia Fragalà ${ }^{1}$, Giorgio Ivan Russo ${ }^{1}$, Alessandro Di Rosa ${ }^{1}$, Raimondo Giardina ${ }^{1}$, Salvatore Privitera ${ }^{1}$, Vincenzo Favilla ${ }^{1}$, \\ Francesco Patti' ${ }^{2}$ Blayne Welk ${ }^{3}$, Sebastiano Cimino ${ }^{1}$, Tommaso Castelli ${ }^{1}$, Giuseppe Morgia ${ }^{1}$ \\ ${ }^{1}$ Department of Urology, University of Catania, Catania, Italy \\ ${ }^{2}$ Department G.F. Ingrassia, Section of Neurosciences, University of Catania, Catania, Italy \\ ${ }^{3}$ Division of Urology, Department of Surgery, Western University, London, ON, Canada
}

Purpose: To determine the relationship between the neurogenic bladder symptoms score (NBSS) and urodynamic examination in patients affected by multiple sclerosis (MS) and related lower urinary tract dysfunction (LUTD).

Methods: We recruited 122 consecutive patients with MS in remission and LUTD from January 2011 to September 2013 who underwent their first urodynamic examination. Neurological impairment was assessed using the Expanded Disability Status Scale (EDSS) and bladder symptoms were studied with the NBSS.

Results: Median NBSS was 20.0 (interquartile range, 12.75-31.0). Neurogenic detrusor overactivity (NDO) was discovered in 69 patients (56.6\%). The concordance between patients with NDO and maximum detrusor pressure during involuntary detrusor contraction (PdetmaxIDC) $\geq 20.0 \mathrm{~cm} \mathrm{H}_{2} \mathrm{O}$ was 0.89 ( $\kappa$-Cohen; $\mathrm{P}<0.05$ ). Patients with EDSS scores of $\geq 4.5$ had a greater NBSS (25.41 vs. 20.19, $\mathrm{P}<0.05)$, NBSS-incontinence (8.73 vs. 4.71, $\mathrm{P}<0.05)$, NBSS-consequence $(4.51$ vs. $3.13, \mathrm{P}<0.05)$ and NBSS-quality of life ( 2.14 vs. $1.65, \mathrm{P}<0.05)$. The NBSS was not associated with PdetmaxIDC $\geq 20 \mathrm{~cm} \mathrm{H}_{2} \mathrm{O}(\mathrm{P}=0.77)$ but with maximum cystometric capacity $<212 \mathrm{~mL}$ (odds ratio, $0.95 ; \mathrm{P}<0.05$ ).

Conclusions: The NBSS cannot give adequate information the way urodynamic studies can, in patients with MS and LUTD.

Keywords: Multiple Sclerosis; Lower Urinary Tract Dysfunction; Urodynamics; Urinary Bladder, Overactive; Neurogenic Bladder Symptom Score

- Research Ethics: This study was conducted in accordance with the regulatory standards of Good Clinical Practice and the Declaration of Helsinki (1996). The study was approved by the Institutional Research Ethics Committee of the University of Catania.

- Conflict of Interest: No potential conflict of interest relevant to this article was reported.

\section{INTRODUCTION}

Multiple sclerosis (MS) is a chronic neurological disorder characterized by disseminated demyelination of nerve fibers of the brain and spinal cord [1-3]. Lower urinary tract dysfunction
(LUTD) could be a common disorder in these patients. Approximately $75 \%$ of all MS patients will develop voiding dysfunction and LUTD during the course of the disease [4]. In fact, LUTD is secondary to several important changes in neurological control of the detrusor-sphincter function resulting in
Corresponding author: Giorgio Ivan Russo (iD http://orcid.org/0000-0003-4687-7353 Department of Urology, University of Catania, Via Santa Sofia 78, Catania, Italy E-mail: giorgioivan@virgilio.it / Tel: +39-95-3782712 / Fax: +39-95-3782373 • Eugenia Fragalà (ib) http://orcid.org/0000-0002-4779-2012

Submitted: September 7, 2015 / Accepted after revision: October 13, 2015 (c) (1) $($ This is an Open Access article distributed under the terms of the Crecc) ative Commons Attribution Non-Commercial License (http://creativecommons.org/licenses/by-nc/3.0/) which permits unrestricted non-commercial use, distribution, and reproduction in any medium, provided the original work is properly cited. 
neurogenic detrusor overactivity (NDO), neurogenic detrusor underactivity (NDU) and/or detrusor-sphincter dyssynergia (DSD) [5].

Unfortunately, the global assessment of urological symptoms is very difficult to investigate and some patient-reported measures (PROMs) are not conclusive. Other PROMs have been cross-validated, such as the incontinence quality of life scale for spinal cord injury. However, because the items were not developed for patients with neurogenic bladder dysfunction, they may be incomplete or inappropriate.

With regards to valid PROMs, Welk et al. [6] have demonstrated that the neurogenic bladder symptom score (NBSS) could be used to evaluate neurogenic bladder dysfunction-related symptoms.

The aim of this study was to determine the relationship between the NBSS and urodynamic examination in a cohort of MS patients with LUTD and to investigate its relationship with other PROMs of sexual dysfunction and disability.

\section{MATERIALS AND METHODS}

We enrolled 122 consecutive patients with MS in remission and LUTD who underwent their first urodynamic examination from January 2011 to September 2013. Criteria for inclusion were: diagnosis of MS according to the McDonald Revised criteria [7]. Indication for urodynamic examination was defined as following: frequency $\geq 8$ micturition per day or $\geq 1$ during the night, urgency and/or urinary incontinence. Exclusion criteria has been reported in a previous study $[8,9]$ and included: history of hysterectomy, vaginal surgery, or stress urinary incontinence; history of antidepressant, anticonvulsant, and anxiolytic drug use; nitrite-positive urinary tract infection; previous surgical treatment for benign prostatic obstruction; or severe benign prostatic obstruction.

Baseline examination included urinalysis, ultrasonography of the upper urinary tract, postvoid ultrasonography, and a full urodynamic study according to the 2002 International Continence Society (ICS) [10]. NDO, DSD, or NDU were defined according to the 2002 ICS Standardization Report on terminology of lower urinary tract function [11-13].

Depression and anxiety were evaluated by the Hamilton Depression Scale (HAM-D) [14] and the Hamilton Anxiety Scale (HAM-A) [15], while neurological impairment was assessed using the Expanded Disability Status Scale (EDSS) [16]. Sexual function was assessed with the Italian Female Sexual Function
Index (FSFI) [17] and the International Index of Erectile Function-15 (IIEF-15) [18]. Sexual function was categorized by the summary score and estimated as "good" (60-75), "fair" (44-59), and "poor" (5-43) [19].

Bladder symptoms were investigated with the NBSS as reported by Welk et al. [6]. The NBSS contains 22 questions, which focus on incontinence, storage and voiding symptoms, and urinary complications associated with neurogenic bladder dysfunction. Two additional questions address bladder management and urinary specific QoL. Items use an adjectival scale with 4 or 5 ordinal responses. An adjectival scale is a symptom scale, which attempts to capture objective signs and symptoms, in contrast to a QoL instrument, which measures subjective responses related to social, emotional, and physical functioning.

The original English version of the NBSS was translated into Italian by two native Italian-speaking, independent, professional translators. Several physicians and a native English-speaking translator examined this "translation-back-translation" process, until all participants agreed that the original and back translated versions were equivalent. All participants provided written informed consent before enrollment and the study was conducted in accordance with the regulatory standards of Good Clinical Practice and the Declaration of Helsinki (1996). The study was approved by the Institutional Research Ethics Committee of the University of Catania.

Continuous variables, presented as mean \pm standard deviations and differences between groups, were tested by Student $\mathrm{t}$ test or Mann-Whitney test, according to their normal or nonnormal distribution, respectively (normality of variables' distribution was tested by Kolmogorov-Smirnov test). The qualitative data was tested using the chi-square test or Fisher exact test, as appropriate.

The reliability of the NBSS was calculated using Cronbach alpha test. Multivariate logistic regression analyses were carried out to identify variables for predicting detrusor overactivity (DO), maximum cystometric capacity (MCC), and bladder compliance. The cutoff of maximum detrusor pressure during involuntary detrusor contraction (PdetmaxIDC) $\geq 20 \mathrm{~cm} \mathrm{H}_{2} \mathrm{O}$, MCC $<212 \mathrm{~mL}, \mathrm{NBSS} \geq 20$ and bladder compliance $\leq 3(\mathrm{~mL} /$ $\mathrm{cm} \mathrm{H}_{2} \mathrm{O}$ ) were based on the median of the cohort and included in the multivariate logistic regression analysis. The cutoff of EDSS $\geq 4.5$ was based on a previous report [20]. Predictive accuracy of the model was assessed in terms of the area under the receiver operating characteristics curve value, incorporating all independent predictors. One thousand bootstrap resamples 
were used to reduce over fit bias. Bootstrapping is a general approach to statistical inference based on building a sampling distribution for a statistic by resampling from the data at hand.

All tests were completed using IBM SPSS Statistics ver. 19.0 (IBM Co., Armonk, NY, USA) and for all statistical comparisons significance was considered as $\mathrm{P}<0.05$.

\section{RESULTS}

Table 1 lists the baseline characteristics of patients included. Seventy-two subjects (59.0\%) were female and $50(41.0 \%)$ were male. Median age was 46.0 years (interquartile range [IQR], 41.5-53.5), median NBSS was 20.0 (IQR, 12.75-31.0). NDO was diagnosed in 69 patients (56.6\%) after urodynamic test. The $\kappa$-Cohen test demonstrated a concordance of 0.89 between patients with $\mathrm{NDO}$ and Pdetmax $\geq 20.0 \mathrm{~cm} \mathrm{H}_{2} \mathrm{O}(\mathrm{P}<0.05)$.

The Cronbach alpha coefficients for total and domain score were sufficiently high, ranging from 0.89 to 0.95 for the total sample. The test-retest procedure revealed that the concordance correlation coefficient was very high for both NBSS total score (Pearson $\mathrm{P}=0.91$ ) and for each domain (Pearson $\mathrm{P}$ always $>0.90$ ).

Ninety-five (77.9\%) had bladder management with spontaneous voiding while 27 (22.1\%) used clean intermittent catheterization. Patients with EDSS $\geq 4.5$ (more serious impairment) had greater (worse) mean NBSS (25.41 vs. $20.19, \mathrm{P}<0.05$ ), NBSS-incontinence (8.73 vs. 4.71, $\mathrm{P}<0.05)$, NBSS-consequence ( 4.51 vs. $3.13, \mathrm{P}<0.05)$ and NBSS-QoL (2.14 vs. $1.65, \mathrm{P}<0.05)$.

Table 2 lists the clinical and urodynamic findings according to NBSS cutoff. Patients with NBSS $\geq 20$ had reduced values of MCC (131.0 mL vs. $212 \mathrm{~mL}, \mathrm{P}<0.01)$.

A positive association was found between the NBSS and EDSS, HAM-A, and HAM-D and negative between NBSS and IIEF-15 and FSFI (Table 3). Significant associations were found on linear regression analysis between NBSS-QoL and MCC $(r=-0.18, \mathrm{P}<0.05)$ and compliance $(r=-0.19, \mathrm{P}<0.05)$ but not with PdetmaxIDC $(r=0.15, \mathrm{P}=0.09)$. The NBSS was not demonstrated to independently predict PdetmaxIDC $\geq 20 \mathrm{~cm} \mathrm{H}_{2} \mathrm{O}$ $(\mathrm{P}=0.77$ ) while it weakly predicted $\mathrm{MCC}<212 \mathrm{~mL}$ (odds ratio [OR], 0.95; 95\% confidence interval, 0.91-0.99; $\mathrm{P}<0.05$ ).

The accuracy of the base model for predicting PdetmaxIDC $\geq 20 \mathrm{~cm} \mathrm{H}_{2} \mathrm{O}$ was 0.80 without significant gaining in accuracy when adding the NBSS. On the contrary, the base models for predicting MCC $<212 \mathrm{~mL}$ were improved from 0.77 to 0.79 when adding NBSS, but without statistical significance.
Table 1. Demographics, neurological, sexual, and urodynamic characteristics of patients included in the study

\begin{tabular}{|c|c|}
\hline Characteristic & Value \\
\hline $\begin{array}{l}\text { Sex } \\
\text { Male } \\
\text { Female }\end{array}$ & $\begin{array}{l}50(41.0) \\
72(59.0)\end{array}$ \\
\hline $\begin{array}{l}\text { Multiple sclerosis variants } \\
\text { Relapsing remittent } \\
\text { Primary progressive } \\
\text { Secondary progressive }\end{array}$ & $\begin{array}{l}85(69.7) \\
15(12.3) \\
22(18.0)\end{array}$ \\
\hline Age (yr) & $46.0(41.5-53.5)$ \\
\hline EDSS & $4.5(2.9-6.0)$ \\
\hline Duration of disease (mo) & $156.0(60.0-231.0)$ \\
\hline HAM-A & $12.0(8.0-16.2)$ \\
\hline HAM-D & $13.0(9.0-19.5)$ \\
\hline NBSS total score & $20.0(12.75-31.0)$ \\
\hline Incontinence subscale & $0(0.0-11.0)$ \\
\hline Storage + voiding subscale & $10.0(7.75-13.0)$ \\
\hline Consequences subscale & $4.0(1.0-6.0)$ \\
\hline QoLitem & $2.0(1.0-3.0)$ \\
\hline NBSS $\geq 20$ & $63(51.6)$ \\
\hline $\begin{array}{l}\text { IIEF-15 } \\
\text { IIEF-EF } \\
\text { IIEF-IS } \\
\text { IIEF-OF } \\
\text { IIEF-SD } \\
\text { IIEF-OS }\end{array}$ & $\begin{array}{c}41.5(22.0-57.0) \\
16.0(7.7-24.0) \\
7.0(4.0-10.2) \\
7.0(2.0-10.0) \\
7.0(4.0-8.0) \\
4.0(2.0-8.0)\end{array}$ \\
\hline Male sexual dysfunction (IIEF-15<60) & $40(80.0)$ \\
\hline $\begin{array}{l}\text { FSFI } \\
\text { FSFI-Desire } \\
\text { FSFI-Arousal } \\
\text { FSFI-Lubrication } \\
\text { FSFI-Orgasm } \\
\text { FSFI-Satisfaction } \\
\text { FSFI-Pain }\end{array}$ & $\begin{array}{c}16.0(2.0-25.5) \\
3.0(1.2-4.8) \\
2.1(0.0-4.1) \\
2.1(0.0-4.5) \\
1.2(0.0-2.4) \\
1.6(0.0-4.0) \\
1.4(0.0-6.0)\end{array}$ \\
\hline Female sexual dysfunction $($ FSFI $<26.55)$ & $48(66.6)$ \\
\hline Neurogenic detrusor overactivity & $69(56.6)$ \\
\hline Detrusor underactivity & $24(17.8)$ \\
\hline Detrusor sphincter dyssynergia & $70(51.9)$ \\
\hline $\operatorname{AOFC}\left(\mathrm{cm} \mathrm{H}_{2} \mathrm{O}\right)$ & $28.5(21.4-44.5)$ \\
\hline $\operatorname{MCC}(\mathrm{mL})$ & $153.5(125.0-220.3)$ \\
\hline PdetmaxIDC $\left(\mathrm{cm} \mathrm{H}_{2} \mathrm{O}\right)$ & $34.7(6.8-55.2)$ \\
\hline VpmaxIDC (mL) & $136.0(99.0-170.0)$ \\
\hline Compliance $\left(\mathrm{mL} / \mathrm{cm} \mathrm{H}_{2} \mathrm{O}\right)$ & $10.2(4.0-37.7)$ \\
\hline
\end{tabular}

Values are presented as number (\%) or median (interquartile range). EDSS, Expanded Disability Status Scale; HAM-A, Hamilton Anxiety Scale; HAM-D, Hamilton Depression Scale; NBSS, neurogenic bladder symptoms score; IIEF-15, International Index of Erectile Function; IIEF-EF, IIEF-erectile function; IIEF-IS, IIEF-intercourse satisfaction; IIEF-OF, IIEF-orgasmic function; IIEF-SD, IIEF-sexual desire; IIEF-OS, IIEF-overall satisfaction; FSFI, Female Sexual Function Index; AOFC, amplitude of the first overactive contraction; MCC, maximum cystometric capacity; PdetmaxIDC, maximum detrusor pressure during involuntary detrusor contraction (IDC); VpmaxIDC, volume at first IDC. 
Table 2. Clinical and urodyamics findings according to NBSS cutoff

\begin{tabular}{|c|c|c|c|}
\hline Variable & NBSS $<20(n=59)$ & NBSS $\geq 20(n=63)$ & $\mathrm{P}$-value \\
\hline Age (yr) & $47.5(42.0-56.50)$ & $46.0(37.0-55.0)$ & 0.578 \\
\hline Duration of disease (mo) & $90.0(60.0-165.0)$ & $168.0(36.0-216.0)$ & $<0.01$ \\
\hline EDSS & $4.0(2.0-5.0)$ & $4.0(3.5-7.5)$ & 0.430 \\
\hline HAM-A & $12.0(8.25-23.0)$ & $11.0(8.0-23.0)$ & 0.320 \\
\hline HAM-D & $10.0(8.50-19.0)$ & $16.0(9.0-22.0)$ & $<0.01$ \\
\hline IIEF-EF & $18.0(8.5-24.7)$ & $11.0(5.0-17.0)$ & 0.372 \\
\hline IIEF-IS & $9.0(4.5-11.7)$ & $7.0(3.0-9.0)$ & 0.350 \\
\hline IIEF-OF & $8.0(2.0-10.0)$ & $6.0(2.0-9.0)$ & 0.592 \\
\hline IIEF-SD & $6.5(4.5-8.0)$ & $7.0(6.0-8.0)$ & 0.092 \\
\hline IIEF-OS & $5.0(2.0-8.0)$ & $4.0(2.0-4.0)$ & 0.479 \\
\hline $\mathrm{MCC}(\mathrm{mL})$ & $212.0(130.0-357.0)$ & $131.0(117.0-225.0)$ & $<0.01$ \\
\hline NDO, n (\%) & $26(44.1)$ & $37(58.7)$ & 0.620 \\
\hline PdetmaxIDC $\left(\mathrm{cm} \mathrm{H}_{2} \mathrm{O}\right)$ & $39.9(6.2-76.2)$ & $85.9(63.6-104.0)$ & 0.121 \\
\hline Compliance & $10.8(2.4-41.8)$ & $3.3(1.2-6.2)$ & 0.357 \\
\hline FSFI & $14.6(1.5-27.3)$ & $16.0(2.0-25.7)$ & 0.829 \\
\hline FSFI-Desire & $3.3(1.2-5.7)$ & $3.0(1.2-4.6)$ & 0.167 \\
\hline FSFI-Arousal & $2.1(0.3-4.8)$ & $3.0(0-4.1)$ & 0.328 \\
\hline FSFI-Lubrication, & $2.4(0-4.8)$ & $3.4(0-4.5)$ & 0.021 \\
\hline FSFI-Orgasm & $1.2(0-2.3)$ & $2.2(0-3.5)$ & $<0.01$ \\
\hline FSFI-Satisfaction & $2.4(0-4.6)$ & $2.0(0.2-3.9)$ & 0.680 \\
\hline FSFI-Pain & $1.4(0-6.0)$ & $1.6(0-5.9)$ & 0.467 \\
\hline
\end{tabular}

Values are presented as median (interquartile range) unless otherwise indicated.

NBSS, neurogenic bladder symptoms score; EDSS, Expanded Disability Status Scale; HAM-A, Hamilton Anxiety Scale; HAM-D, Hamilton Depression Scale; IIEF, International Index of Erectile Function; IIEF-EF, IIEF-erectile function; IIEF-IS, IIEF-intercourse satisfaction; IIEF-OF, IIEF-orgasmic function; IIEF-SD, IIEF-sexual desire; IIEF-OS, IIEF-overall satisfaction; MCC, maximum cystometric capacity; NDO, neurogenic detrusor overactivity; PdetmaxIDC, maximum detrusor pressure during involuntary detrusor contraction; FSFI, Female Sexual Function Index.

Table 3. Spearman correlation between variables

\begin{tabular}{|c|c|c|c|c|c|c|c|c|c|}
\hline \multirow{2}{*}{ NBSS } & \multicolumn{9}{|c|}{ Spearman rho } \\
\hline & MCC & Pdetmax & PdetmaxIDC & Compliance & HAM-A & HAM-D & EDSS & FSFI & IIEF-15 \\
\hline Total score & $-0.213^{*}$ & $-0.401^{* *}$ & -0.005 & -0.086 & $0.447^{* *}$ & $0.389^{* *}$ & $0.278^{* *}$ & $-0.228^{*}$ & $-0.194^{*}$ \\
\hline Incontinence & -0.154 & $-0.472^{* *}$ & -0.050 & 0.009 & $0.326^{* *}$ & $0.302^{* *}$ & $0.332^{* *}$ & -0.149 & -0.219 \\
\hline Storage + voiding & -0.097 & $-0.200^{*}$ & 0.033 & -0.127 & $0.369^{* *}$ & $0.312^{* *}$ & 0.121 & -0.206 & -0.186 \\
\hline Consequence & $-0.197^{*}$ & $-0.197^{*}$ & -0.028 & -0.060 & $0.379^{* *}$ & $0.384^{* *}$ & $0.254^{* *}$ & $-0.446^{* *}$ & -0.102 \\
\hline QoL & $-0.291^{* *}$ & $-0.229^{*}$ & 0.076 & $-0.229^{*}$ & $0.474^{* *}$ & $0.408^{* *}$ & $0.398^{* *}$ & $-0.329^{* *}$ & $-0.457^{* *}$ \\
\hline
\end{tabular}

NBSS, neurogenic bladder symptoms score; MCC, maximum cystometric capacity; Pdetmax, maximum detrusor pressure; PdetmaxIDC, Pdetmax during involuntary detrusor contraction; HAM-A, Hamilton Anxiety Scale; HAM-D, Hamilton Depression Scale; EDSS, Expanded Disability Status Scale; FSFI, Female Sexual Function Index; IIEF, International Index of Erectile Function; QoL, quality of life.

${ }^{*} \mathrm{P}<0.05$. ${ }^{* *} \mathrm{P}<0.01$. 


\section{DISCUSSION}

The findings of this study suggest that the NBSS was initially related to anxiety, depression, and disability. After urodynamic examination, the NBSS was independently related to MCC, but not to NDO.

It is generally known that MS substantially determines a generalized demyelination process that interrupts the continuity of the neural pathways and alters the neural function that is essential for normal sexual activity and urinary function [21].

LUTD is very common in MS and can occur in different urodynamic form, like NDO in $34 \%-99 \%$ of cases, NDU in $0 \%-40 \%$ of cases, or DSD in $5 \%-83 \%$ of cases [22]. Although the epidemiology of DO may consistently differ on the basis of the definitions used in literature, a recent meta-analysis showed a prevalence ranging from $27 \%$ to $91 \%$ [23]. The pathology of neurogenic bladder is often associated with alterations of the electromechanical properties of the detrusor smooth muscle, including increased detrusor excitability [24].

In this context, several PROMs have been introduced in order to identify possible patterns of LUTD and to try to investigate patient responses to medical therapy.

Very recently, NBSS has been designed specifically to assess signs and symptoms related to neurogenic bladder dysfunction. Previous studies generally focused on incontinence, but the three NBSS domains better represent the spectrum of neurogenic bladder dysfunction and the associated complications [6].

We have also recently showed that sexual QoL assessed through the MS Intimacy and Sexuality Questionnaire, as well as IIEF-15 and FSFI was significantly impaired by neurological disability (EDSS), suggesting the needs of a global assessment in MS patients, including sexual function and QoL.

However, one could argue that this PROMs should be also related with urodynamic findings due to the alterations of neurological pathways in MS that could influence sexual function as well as bladder function.

Precisely to this regard, we have demonstrated in patients with neurogenic bladder dysfunction the level of PdetmaxIDC $\geq 20$ $\mathrm{cm} \mathrm{H}_{2} \mathrm{O}, \mathrm{MCC}<135 \mathrm{~mL}$ and compliance $\leq 3 \mathrm{~mL} / \mathrm{cm} \mathrm{H}_{2} \mathrm{O}$ were predictors of moderate-severe erectile dysfunction, strengthening the hypothesis of a common link between bladder and erectile dysfunction.

Unfortunately, one of the most important challenges is the true relationship between PROMs of LUTD and the objective evaluation of bladder dysfunction after urodynamic examination.
Herein, we showed that NBSS did not independently predict PdetmaxIDC $\geq 20 \mathrm{~cm} \mathrm{H}_{2} \mathrm{O}(\mathrm{P}=0.77)$ but weakly predicted $\mathrm{MCC}<212 \mathrm{~mL}(\mathrm{OR}, 0.95 ; \mathrm{P}<0.05)$ with no statistical significance in gaining accuracy when compared to the base model.

Not surprisingly, the NBSS-QoL subscores were related to MCC and compliance. It should be noticed that many reports demonstrated a negative impact between QoL and MS alterations, secondary to severe neurological disability, depression, and other psychiatric disorder that can arise during the course of MS [25].

After external validation, NBSS is a valuable tool that can investigate QoL and different aspects of bladder dysfunction, but it cannot replace urodynamic examination in MS patients with LUTD.

However, this study had some limitations. It was a cross-sectional study and we obtained our sample from an outpatient setting. Second, we did not assess bowel function and several studies have reported a relationship between sexual and bladder dysfunction and bowel function. Finally, the NBSS questionnaire was translated in Italian by a native English-speaking translator; however, it has been not statistically tested.

On the contrary, one possible strength of this study is the evaluation of the relationship between urodynamic findings and NBSS in an external cohort of MS patients with LUTD. The current study demonstrated that NBSS was related to neurological disability expressed as EDSS, but was weakly correlated with some urodynamic variables.

In fact, the urodynamic exam is still the most useful determinant for the assessment of bladder function and cannot be replaced by PROMs, such as the NBSS.

\section{REFERENCES}

1. Gumus H, Akpinar Z, Yilmaz H. Effects of multiple sclerosis on female sexuality: a controlled study. J Sex Med 2014;11:481-6.

2. Lombardi G, Celso M, Bartelli M, Cilotti A, Del Popolo G. Female sexual dysfunction and hormonal status in multiple sclerosis patients. J Sex Med 2011;8:1138-46.

3. Lew-Starowicz M, Rola R. Sexual dysfunctions and sexual quality of life in men with multiple sclerosis. J Sex Med 2014;11:1294-301.

4. DasGupta R, Fowler CJ. Sexual and urological dysfunction in multiple sclerosis: better understanding and improved therapies. Curr Opin Neurol 2002;15:271-8.

5. de Seze M, Ruffion A, Denys P, Joseph PA, Perrouin-Verbe B; GENULF. The neurogenic bladder in multiple sclerosis: review of 
the literature and proposal of management guidelines. Mult Scler 2007;13:915-28.

6. Welk B, Morrow S, Madarasz W, Baverstock R, Macnab J, Sequeira $K$. The validity and reliability of the neurogenic bladder symptom score. J Urol 2014;192:452-7.

7. Polman CH, Reingold SC, Banwell B, Clanet M, Cohen JA, Filippi M, et al. Diagnostic criteria for multiple sclerosis: 2010 revisions to the McDonald criteria. Ann Neurol 2011;69:292-302.

8. Iacovelli E, Gilio F, Meco G, Fattapposta F, Vanacore N, Brusa L, et al. Bladder symptoms assessed with overactive bladder questionnaire in Parkinson's disease. Mov Disord 2010;25:1203-9.

9. Palleschi G, Pastore AL, Stocchi F, Bova G, Inghilleri M, Sigala S, et al. Correlation between the overactive bladder questionnaire (OAB-q) and urodynamic data of Parkinson disease patients affected by neurogenic detrusor overactivity during antimuscarinic treatment. Clin Neuropharmacol 2006;29:220-9.

10. Schäfer W, Abrams P, Liao L, Mattiasson A, Pesce F, Spangberg A, et al. Good urodynamic practices: uroflowmetry, filling cystometry, and pressure-flow studies. Neurourol Urodyn 2002;21:261-74.

11. Abrams P, Cardozo L, Fall M, Griffiths D, Rosier P, Ulmsten U, et al. The standardisation of terminology of lower urinary tract function: report from the Standardisation Sub-committee of the International Continence Society. Neurourol Urodyn 2002;21:167-78.

12. van Koeveringe GA, Vahabi B, Andersson KE, Kirschner-Herrmans R, Oelke M. Detrusor underactivity: a plea for new approaches to a common bladder dysfunction. Neurourol Urodyn 2011;30:723-8.

13. Gammie A, Clarkson B, Constantinou C, Damaser M, Drinnan M, Geleijnse G, et al. International Continence Society guidelines on urodynamic equipment performance. Neurourol Urodyn 2014;33: 370-9.

14. Hamilton M. A rating scale for depression. J Neurol Neurosurg Psychiatry 1960;23:56-62.

15. Hamilton M. The assessment of anxiety states by rating. $\mathrm{Br} \mathrm{J} \mathrm{Med}$ Psychol 1959;32:50-5.
16. Kurtzke JF. Rating neurologic impairment in multiple sclerosis: an expanded disability status scale (EDSS). Neurology 1983;33:144452.

17. Filocamo MT, Serati M, Li Marzi V, Costantini E, Milanesi M, Pietropaolo A, et al. The Female Sexual Function Index (FSFI): linguistic validation of the Italian version. J Sex Med 2014;11:447-53.

18. Rosen RC, Riley A, Wagner G, Osterloh IH, Kirkpatrick J, Mishra A. The international index of erectile function (IIEF): a multidimensional scale for assessment of erectile dysfunction. Urology 1997; 49:822-30.

19. Budweiser S, Enderlein S, Jorres RA, Hitzl AP, Wieland WF, Pfeifer $\mathrm{M}$, et al. Sleep apnea is an independent correlate of erectile and sexual dysfunction. J Sex Med 2009;6:3147-57.

20. Twork S, Wiesmeth S, Spindler M, Wirtz M, Schipper S, Pohlau D, et al. Disability status and quality of life in multiple sclerosis: nonlinearity of the Expanded Disability Status Scale (EDSS). Health Qual Life Outcomes 2010;8:55.

21. Nappi R, Salonia A, Traish AM, van Lunsen RH, Vardi Y, Kodiglu A, et al. Clinical biologic pathophysiologies of women's sexual dysfunction. J Sex Med 2005;2:4-25.

22. Castel-Lacanal E, Game X, Clanet M, Gasq D, De Boissezon X, Guillotreau J, et al. Urinary complications and risk factors in symptomatic multiple sclerosis patients. Study of a cohort of $328 \mathrm{pa}-$ tients. Neurourol Urodyn 2015;34:32-6.

23. Ruffion A, Castro-Diaz D, Patel H, Khalaf K, Onyenwenyi A, Globe D, et al. Systematic review of the epidemiology of urinary incontinence and detrusor overactivity among patients with neurogenic overactive bladder. Neuroepidemiology 2013;41:146-55.

24. Hristov KL, Afeli SA, Parajuli SP, Cheng Q, Rovner ES, Petkov GV. Neurogenic detrusor overactivity is associated with decreased expression and function of the large conductance voltage- and $\mathrm{Ca}(2+)$-activated $\mathrm{K}(+)$ channels. PLoS One 2013;8:e68052.

25. Feinstein A, Feinstein K. Depression associated with multiple sclerosis. Looking beyond diagnosis to symptom expression. J Affect Disord 2001;66:193-8. 